\title{
NÓS VAMOS INVADIR SUA PRAIA
}

\author{
Apresentação
}

\section{Cláudio Celso Alano da Cruz \\ Universidade Federal de Santa Catarina}

Desde o final do século XX, e mais acentuadamente a partir dos primeiros anos do século XXI, a universidade pública brasileira vem passando por algumas transformações que poderíamos, sem o risco de incorrer em exagero, chamar de "profundas". Infelizmente ainda não na ordem do econômico. Tanto os governos tucanos quanto os petistas apenas têm confirmado a insensibilidade atroz que acomete as elites políticas nacionais desde sempre no que diz respeito à distribuição de recursos financeiros para a área da educação, em todos os seus níveis. A nação ainda há de merecer governos que a respeite e que se responsabilizem por fornecer uma EDUCAÇÃO DE QUALIDADE para TODAS as suas crianças e para TODOS os seus jovens. Dito isso, é justo ressaltar que certas medidas essenciais, em outros planos que não o econômico, foram aplicadas nos últimos vinte anos, e foram responsáveis por alguns avanços significativos. Tais medidas têm propiciado, por exemplo, a entrada na universidade pública de determinados grupos sociais que, até então, tinham ficado praticamente impedidos de frequenta-la, com as raríssimas exceções de sempre.

\footnotetext{
* Escritor, professor e pesquisador. Realizou Pós-Doutorado na Universidad de Buenos Aires (2008) e Doutorado em Teoria Literária na Pontifícia Universidade Católica do Rio Grande do Sul (1997). É Bolsista de Produtividade em Pesquisa do CNPq, desenvolvendo atualmente o projeto intitulado "Passagens: Benjamin, Paris, Borges, Buenos Aires". Tem textos publicados no país e no exterior (Estados Unidos, Argentina, Holanda, França, Venezuela, Paraguai, Chile). Ocupa o cargo de Professor Associado III na Universidade Federal de Santa Catarina, onde atua na área de Teoria Literária, Literatura Brasileira e Literatura Argentina, enfocando principalmente os seguintes temas: representações da experiência no espaço (campo/subúrbio/cidade) e no tempo (história/memória) no âmbito da literatura moderna, principalmente a partir de conceitos de Walter Benjamin. Em 2000 adaptou para o palco o romance Os Ratos, de Dyonélio Machado, com temporadas no Teatro Gláucio Gil (Rio de Janeiro) e Teatro do Sesi (Porto Alegre). Publicou, entre outros livros, Marcos IV, 23 (1988), Literatura e Cidade Moderna (1994), Simões Lopes Neto (1999), Arrabaleros (2006), A Ilha do Tesouro e outros poemas (2009) e Recordações de um encenador da província (2010). No mesmo ano publicou Poesia herege (Florianópolis: EdUFSC, 2010) - poemas traduzidos de Evaristo Carriego. Organizou em 2012 uma edição comemorativa ao centenário de publicação de Contos Gauchescos (João Simões Lopes Neto) para a Editora da UFSC. Organizou a coletânea de ensaios Orfeu do Vinicius \& Cia (Florianópolis: EdUFSC, 2015). E-mail: cacruz@cce.ufsc.br.
} 
Particularmente os autodenominados "negros ou pardos" e os descendentes das "comunidades indígenas" estão marcando uma presença cada vez maior na vida acadêmica brasileira. Mesmo se dermos razão aos que consideram ainda muito lenta a sua inserção, não é difícil para aqueles que frequentaram as universidades do país durante o século XX lembrar que, até então, a presença de indivíduos desses grupos era praticamente nenhuma. Se isso ocorria nas Graduações, pode-se imaginar a situação nas Pós-Graduações. Com isso chegamos ao tema central desse Dossiê, que tivemos a oportunidade de organizar graças ao generoso convite e impecável apoio que recebemos da equipe editorial do Anuário de Literatura. O motivo da escolha do tema central - subalternidade - deve-se não simplesmente ao fato de corresponder às nossas atuais pesquisas. Deve-se ao fato, também, de considerarmos que, dadas as transformações acima apontadas, é preciso que ampla e coletivamente nos instrumentalizemos melhor, do ponto de vista teórico e analítico, para responder às novas demandas acadêmicas que já começam a se constituir nesses primeiros anos do século XXI. Falamos tanto em relação ao atual corpo docente como, principalmente, em relação ao corpo discente, ou seja, às novas gerações. Caberá a elas, sem dúvida nenhuma, nas próximas décadas, lidar cotidianamente com essa nova universidade que está surgindo frente aos nossos olhos, e que nos dispensa de qualquer pesquisa empírica para percebermos que, em função disso, a vida acadêmica do país começa, ou em algum momento começará, a ser revolvida de "cima a baixo" por esses contingentes sociais que estão chegando. Para utilizarmos livremente aqui as idéias de um dos textos mais instigantes de Benjamin, esses "novos bárbaros" que estão adentrando os até então "civilizados" corredores e salas universitárias irão trazer com o tempo, sem dúvida nenhuma, um novo sopro de ar e uma energia renovadora para se pensar uma universidade efetivamente brasileira e cosmopolita. Não há dúvida que pouco a pouco estão sendo introduzidos em nossa universidade dos últimos anos indivíduos representantes de uma cultura outra, que poderíamos chamar de cultura subalterna, tal como a conceituou o filósofo marxista Antonio Gramsci. Trata-se de um processo felizmente irreversível e que, se começou em não poucos lugares do país enfrentando às vezes violentas manifestações contrárias, foi se estabelecendo ano a ano, universidade por universidade, cidade por cidade, estado por estado, de forma definitiva. Claro que estamos nos referindo aqui, mais particularmente, à implantação do chamado "sistema de cotas", mas gostaríamos de não fechar a questão apenas nesse aspecto já que, como dissemos acima, foi uma série de ações que ocorreram conjuntamente, e não apenas essa, que, nesse sentido, deve ser apenas considerada a mais decisiva e abrangente. 
Em relação ao tema da subalternidade, convém rastreá-lo, ainda que de forma bem sucinta. A expressão subalterno e outras correlatas iriam surgir e ficar conhecidas, num âmbito mais propriamente teórico, a partir de sua utilização pelo já citado Antonio Gramsci, em especial nos seus Cadernos do cárcere, escritos no período em que se encontrava preso pelo governo fascista italiano, nos anos de 1920 e 1930. Seria na conturbada e extremamente politizada década de 1960 que o Ocidente conheceria uma "descoberta" desse autor que, fora da Itália, até então ainda não tinha sido valorizado de forma ampla como veio a ocorrer naquele momento histórico. Nessa década, muito mais do que a expressão subalterno ou subalternidade, ganhariam destaque as discussões de Gramsci em torno da cultura popular, que não coincidia bem com o que hoje chamamos de cultura subalterna, ainda que, naturalmente, mantenham entre si vínculos estreitos e, muitas vezes, podem ser superpostas. Talvez não seja incorreto dizer que essa distinção, que não se encontrava em Gramsci, devese em grande parte, senão totalmente, aos chamados subaltern studies, uma corrente de pensamento surgida na Índia nas últimas décadas do século XX. No que diz respeito à crítica cultural em particular, um nome dessa corrente ganharia destaque muito especial. Refiro-me, claro, à indiana Gayatri Chakravorty Spivak, que tendo realizado seus estudos de graduação na Universidade de Calcutá iria, logo em seguida, cursar a pós-graduação em literatura comparada na Universidade Cornell, nos Estados Unidos. Isso num momento de grandes transformações políticas, sociais e culturais na América, como de resto no mundo todo. Cabe lembrar que Spivak nasceu em 1942, que podemos estabelecer como sendo o ano "médio" de nascimento daqueles que comporiam a chamada geração de 68, principal protagonista das transformações acima apontadas. Mas seria somente em 1985 que Spivak iria publicar, na revista Wedge, o ensaio que a consagrou no meio acadêmico internacional. Mas para que isso acontecesse, teria que ocorrer uma segunda publicação de seu ensaio, que ocorreu em 1988, na coletânea organizada por Cary Nelson e Larry Grossberg, intitulada Marxism and the interpretation of culture. Refiro-me, claro, ao ensaio Can the subaltern speak? Desde então, o nome de Spivak passou a ser mais conhecido no Brasil. Mas seria somente em 2010, em edição da Editora da UFMG e com o título Pode o subalterno falar?, que a crítica indiana ganharia sua primeira tradução no Brasil. Até aí, nada demais em termos de recepção teórica, seja aqui, seja em outros países periféricos como o Brasil. É tradicionalmente assim que as coisas acontecem em nosso meio acadêmico. Ocorre que, num caso como esse, o fato de ser traduzido ganha uma importância ainda maior, em especial se levarmos em conta que a "complexidade derridiana" do texto (certamente não por acaso o primeiro trabalho importante 
de Spivak foi a tradução da Gramatologia para o inglês) torna a sua leitura em língua estrangeira bem mais difícil, em especial se levarmos em conta esses novos contingentes que estão chegando agora às universidades. Naturalmente que o "capital cultural" desses grupos sociais, para usarmos agora um conceito de Bordieu, tende a ser menor do que o necessário, principalmente no aspecto linguístico, para uma leitura direta de um texto em língua estrangeira, ainda que o tema possa ser dos mais interessantes e pertinentes aos projetos acadêmicos desse conjunto de indivíduos. Não é o lugar adequado para se aprofundar questões como essa, mas não custa lembrar que Peter Burke, em seu já clássico Cultura popular na idade moderna (1978), afirma, de forma muito pertinente, nos parece, que "um estudo sobre a cultura popular é algo que jamais pode ser esotérico". O mesmo pode ser dito para o que hoje estamos chamando de cultura subalterna, e creio que isso não precisa ser demonstrado, dado o grau de obviedade que tal afirmação deixa entrever. Nesse aspecto, inclusive, talvez coubesse alguma crítica a determinados teóricos da subalternidade que tornam por demais obscuras, senão mesmo "esotéricas", tal como a citação de Burke, suas contribuições. Mas isso não importa nesse momento. O caráter decisivo a ser lembrado aqui, em termos do ambiente cultural brasileiro, é que a tradução do famoso ensaio de Spivak torna mais acessível a todos um texto bastante complexo e denso, principalmente para indivíduos que estão se constituindo, mais uma vez lembrando Gramsci, como verdadeiros "intelectuais orgânicos" dessas camadas subalternas no país.

Essas são, em linhas gerais, as idéias e os princípios que nos guiaram, assim como as motivações que nos levaram a propor esse dossiê sobre a questão da subalternidade, no intuito de verificar como tal questão vem se constituindo em nosso país. Esse é o momento, portanto, de agradecer imensamente a todos que enviaram suas contribuições, assim como também aos pareceristas que se dispuseram a colaborar conosco. Pelo número de artigos que nos chegaram, tivemos que ser bastante seletivos. Neste sentido, alguns textos que, sem prejuízo de sua qualidade e relevância, julgamos não se enquadrarem perfeitamente na proposta temática, foram re-encaminhados para publicação em outro setor dessa edição da revista ou em uma edição posterior, desde que aprovados, naturalmente, pelos nossos pareceristas e/ou pelo conselho editorial.

Antes de concluir a apresentação, creio ser importante um último comentário relativo ao material que nos foi enviado, mais particularmente dos lugares de onde vieram. Foi com muita satisfação que pudemos constatar que a origem dos artigos foi a mais variada possível, tendo nos chegado contribuições desde universidades de longa tradição e, portanto, já 
consagradas no meio acadêmico nacional, até as de novas universidades que estão se estabelecendo agora, nestes primeiros anos do século XXI. Além disso, pudemos constatar, com igual satisfação, que o âmbito de inserção da revista Anuário de Literatura confirma-se cada vez mais como sendo efetivamente nacional, o que se comprova pela verificação de que as contribuições vieram das mais variadas regiões do país.

Por fim, resta-nos apenas desejar, ao leitor interessado na temática da subalternidade, que aproveite da melhor forma possível as contribuições que nos foram enviadas. São textos que, com certeza, trazem, no seu conjunto, uma contribuição significativa e instigante para se pensar essa nova área de pesquisa que está se constituindo em nosso país, os subalterns studies, em inglês, ou estudos subalternos, conforme vem sendo chamado no país. Uma área de investigação que pode contribuir muito para estabelecer de modo definitivo em nosso país uma cultura efetivamente democrática e inclusiva. 